\title{
The Transition of Nuclear Disaster Medical System in Japan; the Change after Fukushima Daiichi Nuclear Power Plant Accident and the Activities of Hirosaki University
}

\author{
Takakiyo Tsujiguchi ${ }^{1,2 *}$ \\ ${ }^{1}$ Hirosaki University Graduate School of Health Sciences, Department of Radiation Science, Japan \\ ${ }^{2}$ Hirosaki University Center for Radiation Support and Safety, Japan
}

Received: 㘹 August 18, 2018; Published: 海 August 27, 2018

*Corresponding author: Takakiyo Tsujiguchi, Hirosaki University Graduate School of Health Sciences, Department of Radiation Science; 66-1 Hon-Cho, Hirosaki 036-8564, Japan

\begin{abstract}
The nuclear disaster medical system in Japan has been greatly re-examined by the revision of the Nuclear Emergency Response Guideline for 2015 and has reached the current system. In the current system, "Nuclear Emergency Core Hospitals" are specified as being located mainly in prefectures with nuclear facilities, and "Advanced Radiation Emergency Medical Support Centres" are designated to support dose assessment and medical treatment for serious pollution/radiation exposure patients. "Nuclear Emergency Medical Support Centres" and "Nuclear Emergency Medical Assistance Teams" are designated to provide information/medical care at nuclear disasters nationwide. The two support centres are providing basic training services, such as radiation exposure medicine and patient reception training etc., in various regions and medical institutions. In this paper, I summarize the situation of the establishment of new nuclear disaster medical system in Japan after the accident of Fukushima Daiichi Nuclear Power Plant and summarize the activities of Hirosaki University designated as Advanced Radiation Emergency Medical Support Centres and Nuclear Emergency Medical Support Centres.
\end{abstract}

Keywords: Nuclear Disaster; Radiation Emergency Medicine; Disaster Medicine; Medical System; Human Resource Development; Japan; Medical Support Center; Nuclear Power; Radiological Sciences; Exposure

Abbreviations: NPP: Nuclear Power Plant; NEMSC: Nuclear Emergency Medical Support Center;

AREMSC: Advanced Radiation Emergency Medical Support Center; NECH: Nuclear Emergency Core Hospital; NEMCI: Nuclear Emergency Medical Cooperative Institutions; NEMAT: Nuclear Emergency Medical Assistance Team

\section{Introduction}

\section{The Transition of Nuclear Disaster Medical System in Japan}

Guidelines and laws of radiation emergency medicine have been developed in Japan due to the influence of Three Mile Island Nuclear Power Plant (NPP) accident in 1979, Chernobyl NPP accident in 1986, Tokai village JCO accident in 1999 [1]. However, with the Fukushima Daiichi NPP accident following the Great East Japan Earthquake that occurred in 2011, the radiation emergency medical system in Japan has been transformed into a system to prepare for multiple disasters (nuclear disasters) including radiation accidents. After the Fukushima accident, the Japan Nuclear Regulation Authority released the "Nuclear Emergency Response Guidelines" in 2012, and nuclear power companies, local governments and related medical institutions began to develop disaster management systems [2]. Then, according to the revision of the guideline in 2015, the policy toward the concrete development of the medical system at the time of nuclear disaster was shown, and medical institutions development and personnel training for medical staff are now beginning nationwide.

After 2015, the institutions responsible for medical care in nuclear disasters in Japan were classified into the following four types [2];

a) Nuclear Emergency Medical Support Center (NEMSC),

b) Advanced Radiation Emergency Medical Support Center (AREMSC),

c) Nuclear Emergency Core Hospital (NECH),

d) Nuclear Emergency Medical Cooperative Institutions (NEMCI). 
Four institutions in Japan (Hirosaki University, Fukushima Medical University, Hiroshima University, Nagasaki University) are designated as NEMSC, and in case of emergency, they are responsible for providing emergency medical care for severe exposure / contaminated injured people. In addition, they have Nuclear Emergency Medical Assistance Team (NEMAT; disaster medical dispatching team specialized in nuclear disasters consisting of medical doctors, nurses, radiological technologists) that can support hospitals and information in the acute phase of disasters. Next, five institutions in Japan (National Institute of Radiological Sciences, Hirosaki University, Fukushima Medical University, Hiroshima University, Nagasaki University) are designated as AREMSC, and they are responsible for supporting dose assessment of severe contamination / exposure patients. In peacetime, NEMSC and AREMSC must train human resources related to nuclear disasters. NECH is a large hospital located in the area where the nuclear facility is located and has a mission to provide medical treatment to exposure / contaminated patients as the forefront medical institution in case of emergency.

NECH also has NEMAT, and human resource development and social development are in the works to be able to send and/or receiving support between each other's areas and hospitals. NEMCI is a medical institution or a vocational organization for supporting hospitals in the NECH and local governments according to the situation of the accident and is widely deployed throughout the country. In summary, NECH is at the forefront of medical provision at the time of nuclear disasters. NEMSC and AREMSC respond to serious patients with emergency medical treatment and dose assessment difficulties at NECH. Also, NEMSC and AREMSC play a central role, and it is supposed to also develop human resources in peacetime [2].

\section{Hirosaki University's efforts designated as NEMSC and AREMSC}

In this section, I will introduce what kinds of human resource development activities are actually carried out at the institutions designated as NEMSC and AREMSC. As shown in Figure 1 Hirosaki University has the responsibility to educate medical staff of NECH located at northern part of Japan. Specifically, Hirosaki University holds a training course to learn about medical correspondence in the event of nuclear disasters [3]. In addition, they regularly hold international symposiums so that medical staff and researchers can learn cutting-edge knowledge on dose assessment [4,5]. It is from 2015 that Japan has become the current nuclear disaster medical system as described above, and there are few reports on the medical system and human resource development activities in Japan. Nuclear disasters / radiation accidents are rare events, but when an incident occurs, the impact on society is great, so it is very important to develop human resource and systems in peacetime. I believe that this mini-review is valuable information for various stakeholders such as medical personnel, radiation protection researchers, municipal officials.

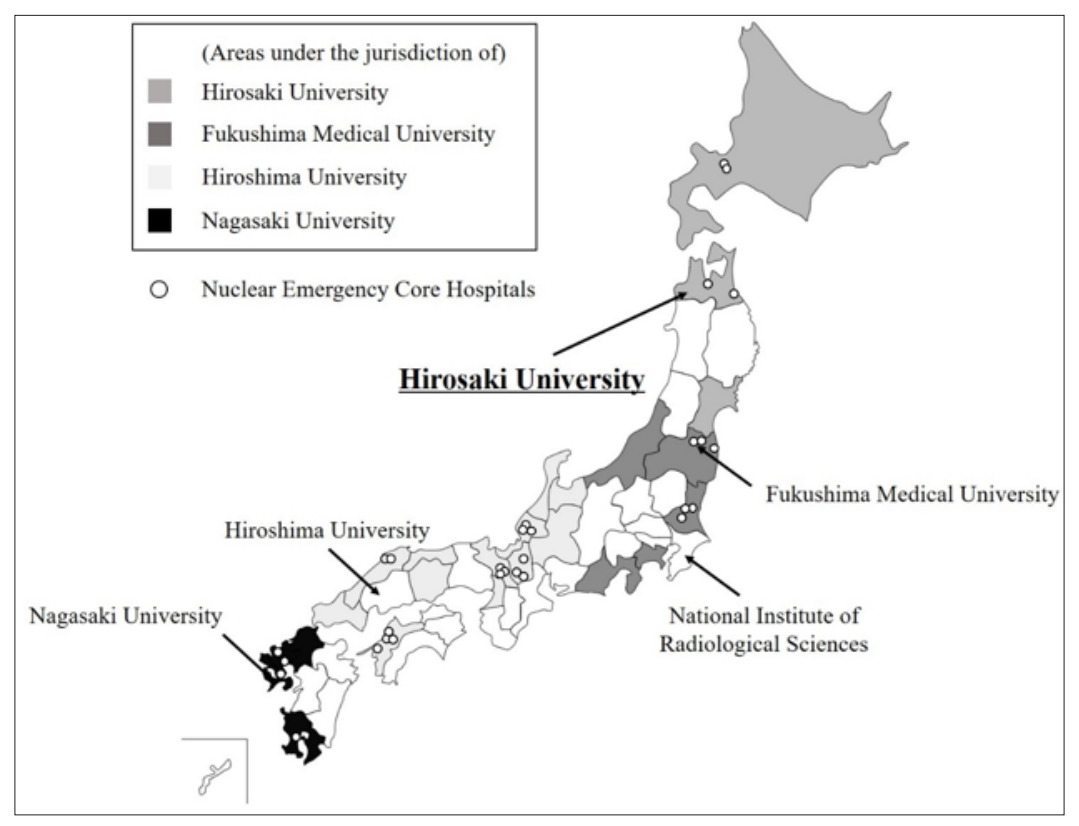

Figure 1: A map of institutions related to nuclear disaster medicine in Japan. It indicates the location of the five institutes designated as NEMSC and AREMSC. In addition, it shows the location of NECH located throughout the country (data on November 1, 2017) [2].

\section{References}

1. Tominaga T, Sagara M, Hachiya M, Tatsuzaki H, Akashi M (2016) Medical response system to radiation emergency in Japan before and after the TEPCO Fukushima Daiichi Nuclear Power Plant Accident. J J Disast Med 21(1): 1-9.
2. Nuclear Regulation Authority (NRA) Japan. NRA websites [online]; Gensiryoku Saigai Taisaku ni Kansuru Shishin tou [Guidelines on nuclear disaster].

3. Yamada A, Watanabe K, Numayama A, Tsujiguchi T, Itaki C et al. (2018) Report on the Training Course for fostering the leaders in Radiation 
Emergency Medicine in Aomori Prefecture 2016. Radiat Environ Med $7(1): 58-64$.

4. Tsujiguchi T, Yamaguchi M, Nanashima N, Chiba M, Terashima S, et al (2016) Report on the $2^{\text {nd }}$ Educational Symposium on radiation and health by Young Scientists (ESRAH 2015). Radiat Environ Med. 5(1): 6571.

ISSN: 2574-1241

DOI: 10.26717/BJSTR.2018.08.001644

Takakiyo Tsujiguchi. Biomed J Sci \& Tech Res

CC (P) This work is licensed under Creative

Submission Link: https://biomedres.us/submit-manuscript.php
5. Matsuya Y, Tsujiguchi T, Yamaguchi M, Kimura T, Mori R et al. (2017) Educational Activity for the Radiation Emergency System in the Northern Part of Japan: Meeting Report on "The 3rd Educational Symposium on Radiation and Health (ESRAH) by Young Scientists in 2016". Radiat Res. 187(6): 641-646.

$\begin{array}{ll}\text { BIOMEDICAL } & \text { Assets of Publishing with us } \\ \text { RESEARCHES } & \text { Global archiving of articles } \\ & \text { - Immediate, unrestricted online access } \\ & \text { - Rigorous Peer Review Process } \\ \end{array}$

